\title{
Modified hydrothermal synthesis and characterization of reduced graphene oxide-silver selenide nanocomposites with enhanced reactive oxygen species generation
}

\author{
Lei Zhu a, Shu Yea, Asghar Ali a , Kefayat Ulla a, Kwang Youn Cho ${ }^{b}$, Won-Chun Oh a,* \\ a Department of Advanced Materials Science \& Engineering, Hanseo University, Seosan-si, Chungnam-do 356-706, Korea \\ ${ }^{\mathrm{b}}$ Korea Institute of Ceramic Engineering and Technology, Seoul 153-801, Korea
}

\section{A R T I C L E I N F O}

Article history:

Received 30 November 2014

Accepted 25 December 2014

Published 20 April 2015

\section{Keywords:}

Graphene

Silver selenide

Sonochemical method

Hydrothermal method

Rhodamine B

Texbrite BA-L

\begin{abstract}
A B S T R A C T
A visible-light photocatalyst containing $\mathrm{Ag}_{2} \mathrm{Se}$ and reduced graphene oxide (RGO) was synthesized by a facile sonochemical-assisted hydrothermal method. X-ray diffraction, scanning electron microscopy with energy-dispersive X-ray analysis, and ultraviolet-visible diffuse reflectance spectroscopy results indicated that the $\mathrm{RGO}-\mathrm{Ag}_{2} \mathrm{Se}$ nanocomposite contained small crystalline $\mathrm{Ag}_{2} \mathrm{Se}$ nanoparticles dispersed over graphene nanosheets and absorbed visible light. The high crystallinity of the nanoparticles increased photocatalytic activity by facilitating charge transport. $\mathrm{N}_{2}$ adsorption-desorption measurements revealed that the $\mathrm{RGO}-\mathrm{Ag}_{2} \mathrm{Se}$ nanocomposite contained numerous pores with an average diameter of $9 \mathrm{~nm}$, which should allow reactant molecules to readily access the $\mathrm{Ag}_{2} \mathrm{Se}$ nanoparticles. The RGO- $\mathrm{Ag}_{2} \mathrm{Se}$ nanocomposite exhibited higher photocatalytic activity than bulk $\mathrm{Ag}_{2} \mathrm{Se}$ nanoparticles to degrade organic pollutant rhodamine $\mathrm{B}$ and industrial dye Texbrite BA-L under visible-light irradiation $(\lambda>420 \mathrm{~nm})$. The generation of reactive oxygen species in RGO- $\mathrm{Ag}_{2} \mathrm{Se}$ was evaluated through its ability to oxidize 1,5-diphenylcarbazide to 1,5-diphenylcarbazone. The small size of the $\mathrm{Ag}_{2} \mathrm{Se}$ nanoparticles in $\mathrm{RGO}-\mathrm{Ag}_{2} \mathrm{Se}$ was related to the use of ultrasonication during their formation, revealing that this approach is attractive to form porous $\mathrm{RGO}-\mathrm{Ag}_{2} \mathrm{Se}$ materials with high photocatalytic activity under visible light.
\end{abstract}

(C) 2015, Dalian Institute of Chemical Physics, Chinese Academy of Sciences. Published by Elsevier B.V. All rights reserved.

\section{Introduction}

The textile, plastic, paper, and pulp industries generate streams of waste containing substantial amounts of organic dyes that are usually non-biodegradable and difficult to remove. Discharging this waste into water bodies without any prior treatment can have severe environmental consequences. The molecules in these effluents usually possess carcinogenic and mutagenic properties, so they can not only harm aquatic ecosystems but also actively or passively pose a major threat to human life [1,2]. Various physical, chemical, and biological methods [3] have been used to treat dyes, including coagulation, flocculation, precipitation, ozonation, oxidation [4] and radiation [5].

Semiconductor photocatalysis has previously been described as a promising option to remove persistent pollutants from contaminated water. Photocatalysis involves the in situ generation and use of highly oxidizing agents, mainly hydroxyl radicals. Hydroxyl radicals can degrade organic pollutants in water to obtain complete mineralization into $\mathrm{CO}_{2}, \mathrm{H}_{2} \mathrm{O}$ and mineral acids such as sulfuric, hydrochloric, and nitric acids.

Silver selenide exists as a low-temperature phase $\left(\beta-\mathrm{Ag}_{2} \mathrm{Se}\right)$

* Corresponding author. Tel: +82-41-660-1337; Fax: +82-41-688-3352; E-mail: wc_oh@hanseo.ac.kr DOI: 10.1016/S1872-2067(14)60275-8 | http://www.sciencedirect.com/science/journal/18722067 | Chin. J. Catal., Vol. 36, No. 4, April 2015 
and high-temperature phase $\left(\alpha-\mathrm{Ag}_{2} \mathrm{Se}\right)$ with the phase transition point at $135{ }^{\circ} \mathrm{C}$ [6]. $\alpha-\mathrm{Ag}_{2} \mathrm{Se}$ is a well-known superionic conductor that is useful as the solid electrolyte in photochargeable secondary batteries. Meanwhile, $\beta-\mathrm{Ag}_{2} \mathrm{Se}$ is a narrow-band-gap semiconductor and has been widely used as a photosensitizer in photographic films and thermochromic materials. Cao et al. [7] synthesized single-crystalline $\mathrm{Ag}_{2} \mathrm{Se}$ complex nanostructures via a solvothermal route and characterized their photocatalytic activity by photodegradation of rhodamine $\mathrm{B}(\mathrm{RhB})$ dye under ultraviolet (UV) light irradiation.

Graphene is a good support for semiconductor nanocrystals because of its unique electronic, mechanical, physical, and chemical properties [8,9]. The flat monolayer structure and charge transfer ability of graphene make it a suitable candidate to anchor $\mathrm{Ag}_{2} \mathrm{Se}$ nanocomposites. In addition, graphene should help to improve the photocatalytic activity of the nanocomposites by suppressing charge recombination. Many approaches, such as hydrothermal [10] and sol-gel methods [11], have been developed to decorate graphene sheets with nanoparticles.

The synthesis of nanomaterials of uniform size and shape and high crystallinity is an important challenge. Various methods to prepare nanomaterials are available, including hydrothermal, microwave, sol-gel, microemulsion, and polyol techniques. However, each of these methods has its own limitations, such as long reaction time, formation of nanomaterials of nonuniform shape and size, particle agglomeration, and expensive solvent [12,13].

Sonochemical synthesis can be used to rapidly prepare nanomaterials of uniform size and shape by employing ultrasound at the frequency range of $18-100 \mathrm{kHz}$ as a source of high energy to generate acoustic cavitation. This phenomenon involves the formation, growth and collapse of cavity bubbles that entrap dissolved gases or vapors surrounding water $[14,15]$. Ultrasonication is important for the initiation or enhancement of catalytic reactions in both homogeneous and heterogeneous systems [16].

In this work, we report a simple, green way to prepare a reduced graphene oxide ( $\mathrm{RGO}$ ) $-\mathrm{Ag}_{2} \mathrm{Se}$ nanocomposite through ultrasonic treatment combined with hydrothermal synthesis. In this process, graphene oxide (GO) is mixed with Ag and Se precursor materials and the resulting solution is irradiated by ultrasonic waves. During the reaction, simultaneous reduction of graphite oxide to graphene and attachment of $\mathrm{Ag}_{2} \mathrm{Se}$ nanoparticles are observed. The evolution of reactive oxygen species is also investigated by the ability of the composite to oxidize 1,5-diphenylcarbazide (DPCI) into 1,5-diphenylcarbazone (DPCO), which can be extracted by organic solvents and displays an obvious absorption signature. The photocatalytic activities of RGO- $\mathrm{Ag}_{2} \mathrm{Se}$ nanocomposites are tested with a model organic dye RhB and industrial dye Texbrite BA-L (TBA) under visible-light radiation.

\section{Experimental}

\subsection{Materials}

Ethylene glycol and anhydrous ethanol were purchased from Daejung Chemical Co. (Korea). GO was prepared using the Hummers-Offeman method [17]. $\mathrm{AgNO}_{3}$, Se metal powder and $\mathrm{NH}_{4} \mathrm{OH}$ (28\%) were purchased from DaeJung Chemicals \& Metal Co., Ltd (Korea). Titanium oxide nanopowder (P25, <25 nm, 99.7\%) with anatase structure was purchased from Sigma-Aldrich Chemistry (USA) for use as a reference sample. TBA was purchased from Texchem Co. Ltd (Korea). RhB $\left(\mathrm{C}_{28} \mathrm{H}_{31} \mathrm{ClN}_{2} \mathrm{O}_{3}, 99.99 \%\right)$ purchased from Samchun Pure Chemical Co., Ltd (Korea) was used as a model pollutant. All chemicals were used without further purification, and all experiments were carried out using distilled water.

\subsection{Synthesis of GO}

Natural graphite powder (10 g) was mixed with concentrated $\mathrm{H}_{2} \mathrm{SO}_{4}(230 \mathrm{~mL})$ at $0{ }^{\circ} \mathrm{C}$ with vigorous magnetic stirring. $\mathrm{KMnO}_{4}$ (30 g) was slowly added to the flask and the temperature was kept below $15^{\circ} \mathrm{C}$. The resulting mixture was stirred at $35^{\circ} \mathrm{C}$ until it became a brownish paste, and then diluted to 150 $\mathrm{mL}$ with deionized (DI) water and kept stirring below $90{ }^{\circ} \mathrm{C}$. After adding water, the container was sealed and kept at $100{ }^{\circ} \mathrm{C}$ with vigorous stirring for $30 \mathrm{~min}$, followed by the dropwise addition of $20 \% \mathrm{H}_{2} \mathrm{O}_{2}$ over $5 \mathrm{~min}$. The mixture was washed sequentially several times with water, acetone and $10 \% \mathrm{HCl}$ solution to remove residual metal ions. The mixture was then heat treated in a dry oven at $90{ }^{\circ} \mathrm{C}$ for $12 \mathrm{~h}$ to obtain graphite oxide powder. To prepare GO, graphite oxide powder (200 mg) was mixed in DI water $(200 \mathrm{~mL}, 1 \mathrm{mg} / \mathrm{mL})$, stirred for $30 \mathrm{~min}$ and then ultrasonicated for $1 \mathrm{~h}$. The resulting solution was filtered, washed several times with hot water and dried in an oven for $6 \mathrm{~h}$ to give GO powder. To obtain graphene as a control sample, GO was reduced by a mild chemical method according to our previous research [18].

\subsection{Synthesis of $\mathrm{Ag}_{2} \mathrm{Se}$}

$\mathrm{Ag}_{2} \mathrm{Se}$ was synthesized by a hydrothermal method. First, solution A was prepared by adding crude Se powder $(0.2 \mathrm{~g})$ to ethylene glycol (50 $\mathrm{mL})$ and stirring the mixture for $1 \mathrm{~h}$ using a magnetic stirrer to ensure homogenous mixing. Second, solution $\mathrm{B}$ was formed by adding an appropriate amount of $\mathrm{AgNO}_{3}$ powder to DI water $(50 \mathrm{~mL})$. Solutions A and B were mixed together and transferred to a Teflon-lined stainless steel autoclave that was then sealed. The contents were then heated at $160{ }^{\circ} \mathrm{C}$ for $12 \mathrm{~h}$. The obtained sample was washed several times with distilled water and dried in a vacuum oven at $90^{\circ} \mathrm{C}$ for $8 \mathrm{~h}$.

\subsection{Synthesis of RGO-Ag2 Se composite}

A RGO- $\mathrm{Ag}_{2}$ Se nanocomposite was prepared by a sonochemical-assisted hydrothermal method. In a typical synthetic procedure, GO (300 mg) and $\mathrm{AgNO}_{3}(22 \mathrm{mg}$ ) were dispersed in ethanol and water $(1: 1 v / v, 100 \mathrm{~mL})$ by ultrasonication for $1 \mathrm{~h}$ using a digital sonifier to obtain a homogeneous GO nanosheet (GONS)/Ag+ solution. Here, $\mathrm{AgNO}_{3}$ was used as a source of $\mathrm{Ag}^{+}$ ions, which were obtained by the hydrolysis of $\mathrm{AgNO}_{3}$ in the presence of water and ethanol. Se powder and $\mathrm{NH}_{4} \mathrm{OH}(6 \mathrm{~mL}$, 
$28 \mathrm{wt} \%$ ) were added, and then the mixture was stirred rapidly at $100{ }^{\circ} \mathrm{C}$ for $8 \mathrm{~h}$. The mixture was transferred to a Teflon-lined stainless steel autoclave that was then sealed. The contents were heated at $160{ }^{\circ} \mathrm{C}$ for $12 \mathrm{~h}$. The reaction mixture was allowed to cool to room temperature and then the precipitate was filtered, washed with distilled water five times, and dried in a vacuum oven.

\subsection{Characterization}

To determine the crystal phase and the composition of the as-prepared samples, X-ray diffraction (XRD) characterization was carried out at room temperature using a diffractometer (XD-D1, Shimata, Japan) with $\mathrm{Cu} K_{\alpha}$ radiation $(\lambda=1.54056 \AA)$ in the range of $2 \theta=10^{\circ}-80^{\circ}$ at a scan speed of $1.2^{\circ} / \mathrm{min}$. Scanning electron microscopy (SEM; JSM-5200, JEOL, Japan) was used to observe the surface state and morphology of the prepared nanocomposite. The morphology of samples was studied by energy-dispersive X-ray spectroscopy (EDX), which was also used for elemental analysis. Transmission electron microscopy (TEM; JEM-2010, JEOL, Japan) at an acceleration voltage of 200 $\mathrm{kV}$ was used to observe the surface state and structure of the photocatalyst composite. TEM was also used to examine the size and distribution of $\mathrm{Ag}_{2} \mathrm{Se}$ nanoparticles on the GONS. Fourier transform infrared (FT-IR) spectroscopy (FTS 3000MX, Biored Co., Korea) was used to characterize the functional groups of graphite oxide and the RGO- $\mathrm{Ag}_{2} \mathrm{Se}$ composites. Diffuse reflectance spectra were obtained using a scanning ultraviolet-visible (UV/Vis) spectrophotometer (Neosys-2000) equipped with an integrating sphere. Raman spectra of the samples were observed using a Raman spectrometer (NRS-3100, Jasco, Japan) with an excitation laser wavelength of $532.06 \mathrm{~nm}$. Decomposition kinetics for the photocatalytic activity assessment were measured using a spectrometer (Optizen POP, Mecasys, Korea).

\subsection{Evaluation of reactive oxygen species}

Experiments were performed according to a reported method [19]. First, four 100-mL transparent volumetric flasks were labeled (a-d). DPCI (10.00 mL, $0.1 \mathrm{mmol} / \mathrm{L})$ was added to each of a-d, followed by $50 \mathrm{mg}$ of sample 1, 2, 3, and 4 to a, b, c, and $d$, respectively. All of the four solutions were then diluted to $100 \mathrm{~mL}$ with double-distilled water. The final DPCI concentration and amount of RGO- $\mathrm{Ag}_{2} \mathrm{Se}$ were $1.00 \mathrm{mmol} / \mathrm{L}$ and $1.00 \mathrm{~g} / \mathrm{L}$, respectively. After $120 \mathrm{~min}$ of irradiation, $10-\mathrm{mL}$ aliquots were taken from each reactor and extracted with benzene. The extracted solutions were diluted to $10 \mathrm{~mL}$ with benzene and their UV-Vis spectra were recorded.

\subsection{Photocatalytic studies}

The photocatalytic activities of $\mathrm{P} 25$, pure $\mathrm{Ag}_{2} \mathrm{Se}$, and RGO- $\mathrm{Ag}_{2} \mathrm{Se}$ nanocomposite were evaluated by the degradation of $\mathrm{RhB}$ solution under irradiation with visible light (8 W, Fawoo, Lumidas-H, Korea, $\lambda>420 \mathrm{~nm}$ ). In an ordinary photocatalytic test performed at room temperature, photocatalyst (0.05 g) was added to $\mathrm{RhB}$ solution $(50 \mathrm{~mL}, 200 \mathrm{mmol} / \mathrm{L})$, which is hereafter considered as the initial concentration $\left(C_{0}\right)$. To better assess the degradation activity of the RGO- $\mathrm{Ag}_{2} \mathrm{Se}$ nanocomposite, the industrial dye TBA was also degraded under the same conditions. Each mixture was sonicated for 10 min and then stirred for $120 \mathrm{~min}$ in the dark to reach adsorption-desorption equilibrium. The first sample was taken out of the mixture just before the light was turned on to determine the dye concentration in the solution after adsorption in the dark, which is henceforth considered as the initial adsorbed concentration $\left(C_{\mathrm{ads}}\right)$. Samples were then removed from the reactor at $30,60,90,120$, and $150 \mathrm{~min}$, and immediately centrifuged to separate any suspended solids. Each clean transparent solution was analyzed by UV-Vis spectroscopy (Optizen POP) in the wavelength range from 250 to $800 \mathrm{~nm}$.

\section{Results and discussion}

\subsection{Characterization results}

To obtain information about the composition of the prepared RGO- $\mathrm{Ag}_{2} \mathrm{Se}$ composite, it was examined by EDX. Fig. 1 shows the EDX microanalysis and elemental mass percentages

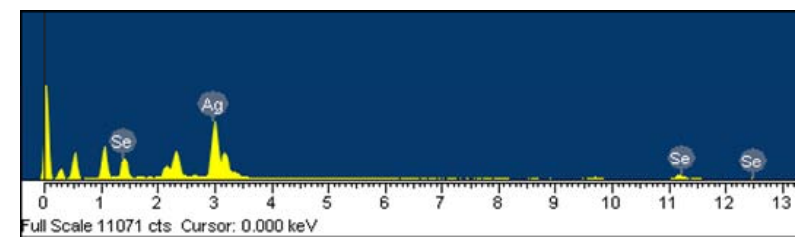

(a)

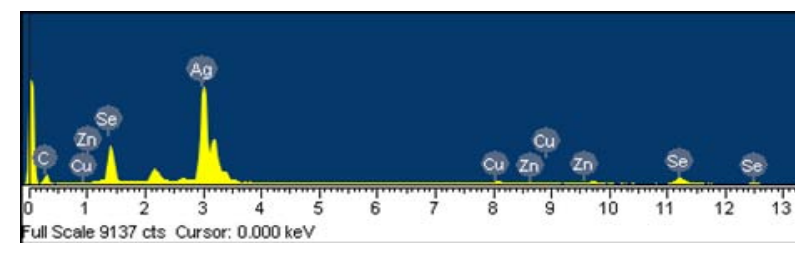

(b)
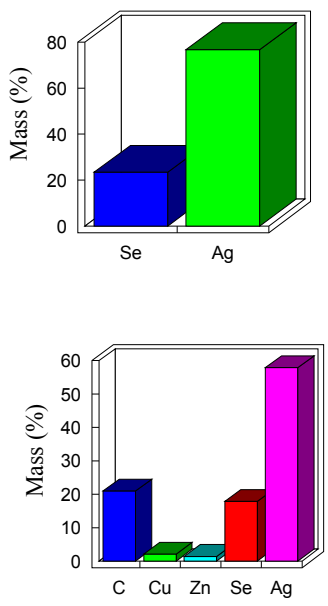

Fig. 1. EDX elemental microanalysis and elemental mass percentages of $\mathrm{Ag}_{2} \mathrm{Se}(\mathrm{a})$ and $\mathrm{RGO}-\mathrm{Ag}_{2} \mathrm{Se}$ composite (b). 
determined for pure $\mathrm{Ag}_{2} \mathrm{Se}$ and the $\mathrm{RGO}-\mathrm{Ag}_{2} \mathrm{Se}$ composite. The main elements were $\mathrm{C}, \mathrm{Ag}$, and $\mathrm{Se}$, as expected. The strong $\mathrm{C}$ signal should mainly originate from the GONS. A very low concentration of impurities was present, which may originate from the experimental procedure. The EDX data confirm that a RGO- $\mathrm{Ag}_{2} \mathrm{Se}$ hybrid was successfully synthesized.

An illustration of the deposition of $\mathrm{Ag}_{2} \mathrm{Se}$ on the GONS is presented in Fig. 2(a). In this approach, $\mathrm{Ag}^{+}$ions coordinated to hydroxyl groups, possibly epoxy or carboxyl groups, on GO [20]. Then, the $\mathrm{Ag}^{+}$ions reacted with $\mathrm{Se}^{2-}$ during hydrothermal treatment to form $\mathrm{Ag}_{2} \mathrm{Se}$ nanoparticles and GO was reduced simultaneously. Fig. 2(b) shows the XRD patterns of the precursors used in this procedure and the product obtained. Graphene exhibits peaks at $25.9^{\circ}$ and $42.7^{\circ}$ corresponding to the (002) and (100) reflections of graphite (JCPDS 01-0646), respectively. The XRD pattern of $\mathrm{Ag}_{2} \mathrm{Se}$ exhibits the characteristic (002), (112), (121), (103), (031), (200), (213), and (134) crystal planes originating from the orthorhombic $\mathrm{Ag}_{2} \mathrm{Se}$ phase, consistent with the results reported by Chen et al. [21], and lattice parameters of $a=0.4331 \mathrm{~nm}, b=0.7061 \mathrm{~nm}$, and $c=0.7763 \mathrm{~nm}$ (JCPDS 20-1063). No signals from any other phases of GO (001) or graphene (002) were detected in the RGO- $\mathrm{Ag}_{2} \mathrm{Se}$ composite, indicating that the oxygen intercalated into the interlayer spacing of graphite was largely removed by chemical reduction [19].

The typical microsurface structure and morphology of the samples were characterized by SEM and TEM, respectively. The SEM image in Fig. 3(a) shows that the $\mathrm{Ag}_{2} \mathrm{Se}$ particles are large squares with good dispersion. The GONS exhibited a flake-like morphology, reflecting its layered microstructure (Fig. 3(b)). The large interlayer spaces and thin-layer edges of graphene can be clearly observed. It is noteworthy that sonochemical synthesis of the RGO- $\mathrm{Ag}_{2} \mathrm{Se}$ composite yielded nanoscale $\mathrm{Ag}_{2} \mathrm{Se}$ particles, as observed in Fig. 3(c), with a favorable morphology and smaller size compared with that of pure $\mathrm{Ag}_{2} \mathrm{Se}$ synthesized by hydrothermal synthesis alone.

Typical TEM images of graphene, $\mathrm{Ag}_{2} \mathrm{Se}$, and RGO- $\mathrm{Ag}_{2} \mathrm{Se}$ are displayed in Fig. 4. The morphology of graphene of thin stacked flakes with a well-defined few-layer structure at the edge is clear in Fig. 4(a). Nanoscale $\mathrm{Ag}_{2} \mathrm{Se}$ is observed in the RGO- $\mathrm{Ag}_{2} \mathrm{Se}$
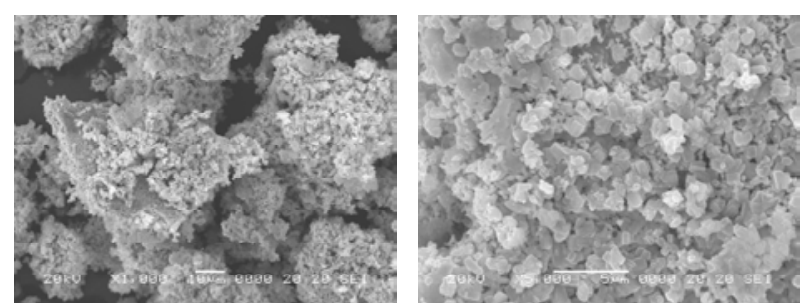

(a)
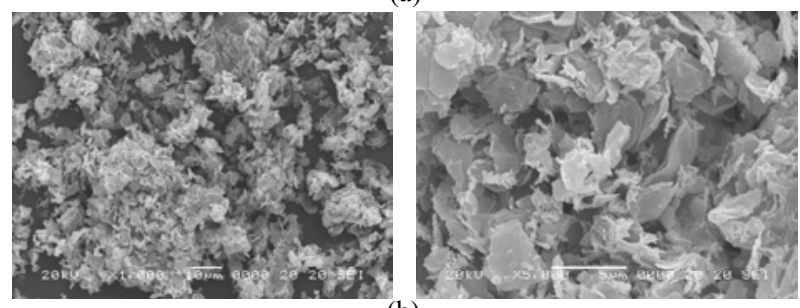

(b)
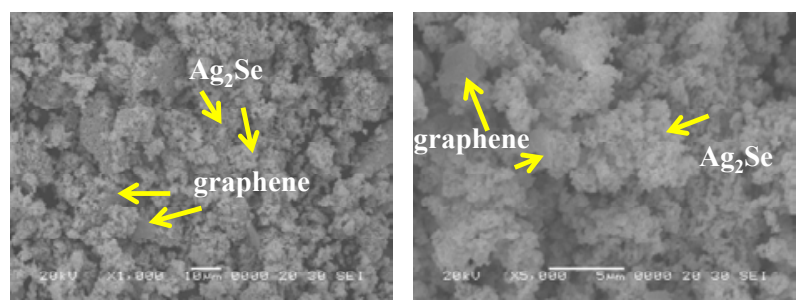

(c)

Fig. 3. SEM images of as-prepared samples. (a) $\mathrm{Ag}_{2} \mathrm{Se}$; (b) Graphene; (c) RGO- $\mathrm{Ag}_{2} \mathrm{Se}$ composite.

composite as well-dispersed nanoparticles with an average size of 8-10 nm (Fig. 4(b)). Ag 2 Se synthesized by a hydrothermal method without ultrasound (inset of Fig. 4(b)) is polycrystalline with defined single crystals with sizes of up to 50-100 nm. These results show that our nanocomposite is composed of well-dispersed $\mathrm{Ag}_{2} \mathrm{Se}$ nanoparticles on GONSs. Therefore, ultrasonic-assisted synthesis of RGO- $\mathrm{Ag}_{2} \mathrm{Se}$ is advantageous over other synthesis methods, and should improve the photocatalytic properties of this material [22].

The FT-IR spectra of crystalline materials show distinct, sharp bands, whereas those of amorphous materials are less well resolved. Fig. 5 presents the FT-IR spectra measured for graphite oxide and the RGO- $\mathrm{Ag}_{2} \mathrm{Se}$ composite. Some carbon
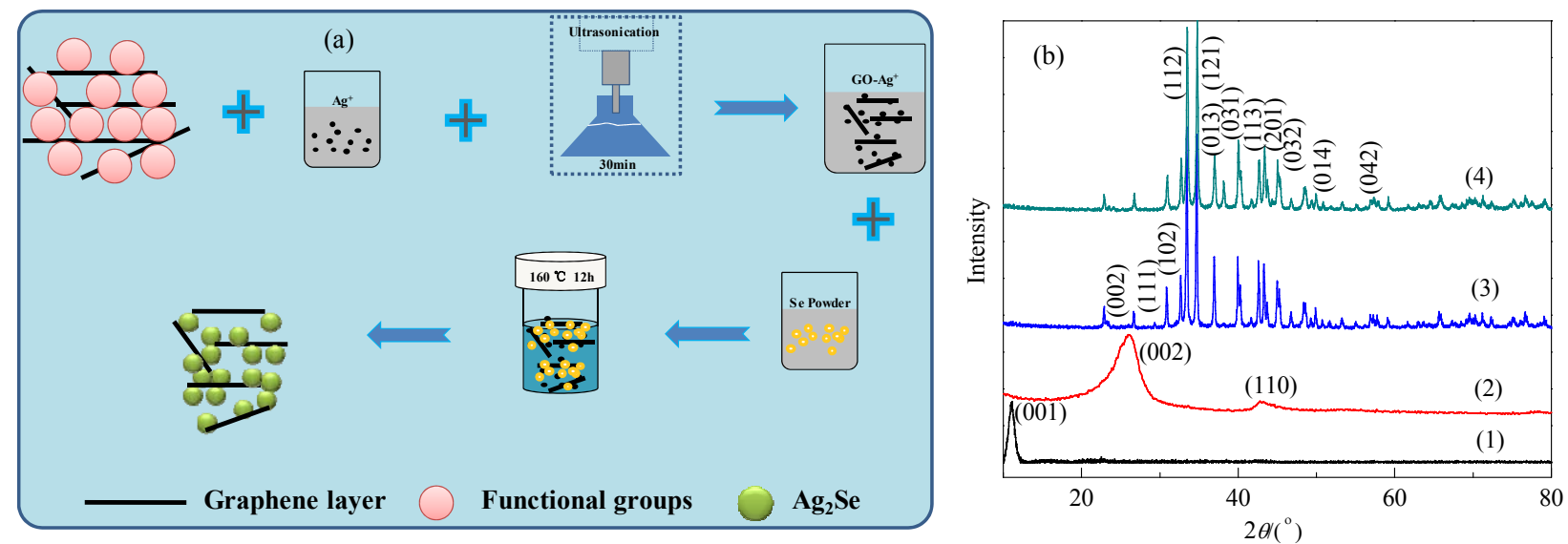

Fig. 2. (a) Schematic illustration of the deposition of $\mathrm{Ag}_{2} \mathrm{Se}$ on grapheme; (b) XRD patterns of pristine graphite oxide (1), graphene (2), $\mathrm{Ag}_{2} \mathrm{Se}(3)$ and RGO- $\mathrm{Ag}_{2} \mathrm{Se}$ composite (4). 


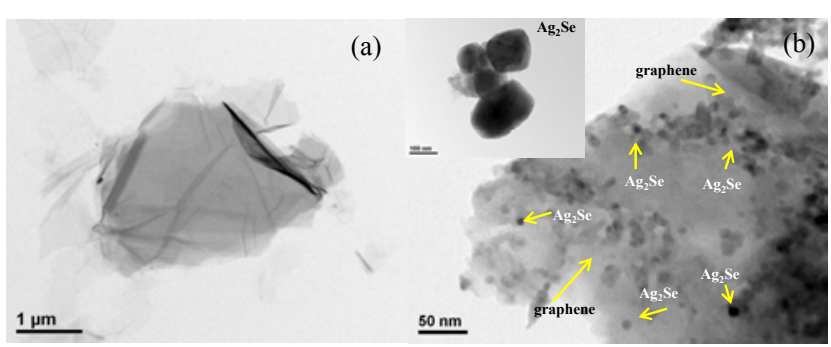

Fig. 4. TEM images of graphene (a) and RGO- $\mathrm{Ag}_{2} \mathrm{Se}$ composite (b). The inset is a TEM image of $\mathrm{Ag}_{2} \mathrm{Se}$ synthesized by a hydrothermal method without ultrasound.

double bonds of graphite oxide nanosheets are oxidized after acidic intercalation and thermal treatment, resulting in the presence of oxygen-containing functional groups such as $-\mathrm{COOH}$ and $-\mathrm{OH}$ on the nanosheet surface $[18,23]$. For GO, the peak at $1619 \mathrm{~cm}^{-1}$ can be assigned to the vibrations of adsorbed water molecules. In addition, GO exhibits a $\mathrm{C}=\mathrm{O}$ carbonyl stretching mode at $1728 \mathrm{~cm}^{-1}, \mathrm{C}-\mathrm{OH}$ stretching mode at $1226 \mathrm{~cm}^{-1}$, and $\mathrm{C}-0$ stretching mode at $1050 \mathrm{~cm}^{-1}$.

The amount and distribution of carboxylic groups on the GONS strongly influence the further modification of the sheets with nanoparticles. Positive metal ions in the system can interact with the carboxylic groups of the GONS via electrostatic attraction and serve as nucleation precursors [24]. In the FT-IR spectrum of the RGO- $\mathrm{Ag}_{2} \mathrm{Se}$ composite, the weak peak at 1052 $\mathrm{cm}^{-1}$ was assigned to $\mathrm{C}-\mathrm{OH}$ groups. Peaks for $\mathrm{C}-\mathrm{O}$ and $\mathrm{C}=\mathrm{O}$ functional groups were observed at approximately 1427 and $1728 \mathrm{~cm}^{-1}$, respectively. Comparison of the spectra reveals lower peak intensity for functional groups in oxidized graphene compared with that for graphite oxide. This is because some of the functional groups combined with $\mathrm{Ag}_{2} \mathrm{Se}$ particles and were removed during reduction of GO to graphene [19].

A $\mathrm{N}_{2}$ adsorption-desorption isotherm and pore-size distribution curve for the $\mathrm{RGO}-\mathrm{Ag}_{2} \mathrm{Se}$ composite are depicted in Fig. 6. The formation of a type-IV adsorption isotherm confirmed the presence of numerous mesopores on the surface of the sample. Characteristic features of type-IV isotherms are hysteresis, which is associated with capillary condensation taking place in mesopores, and limited uptake at high $p / p_{0}$. The initial part of the type-IV isotherm is attributed to monolayer-multilayer adsorption because it follows the same path as the corre-

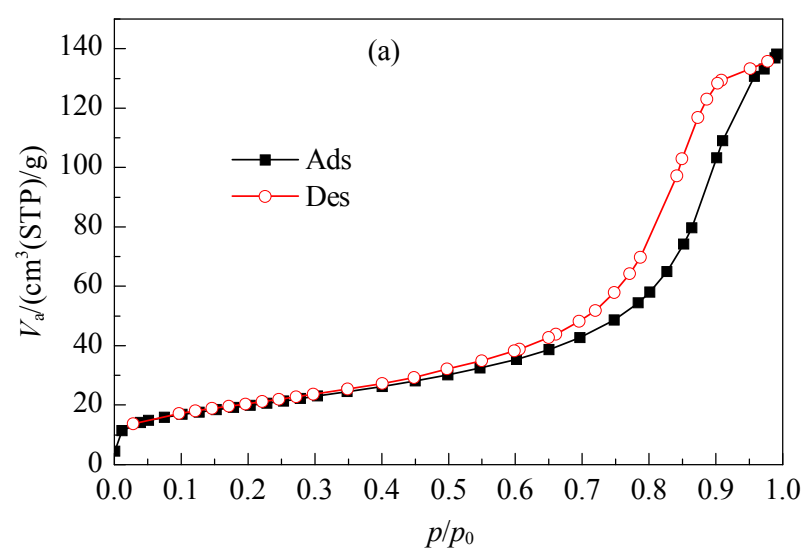

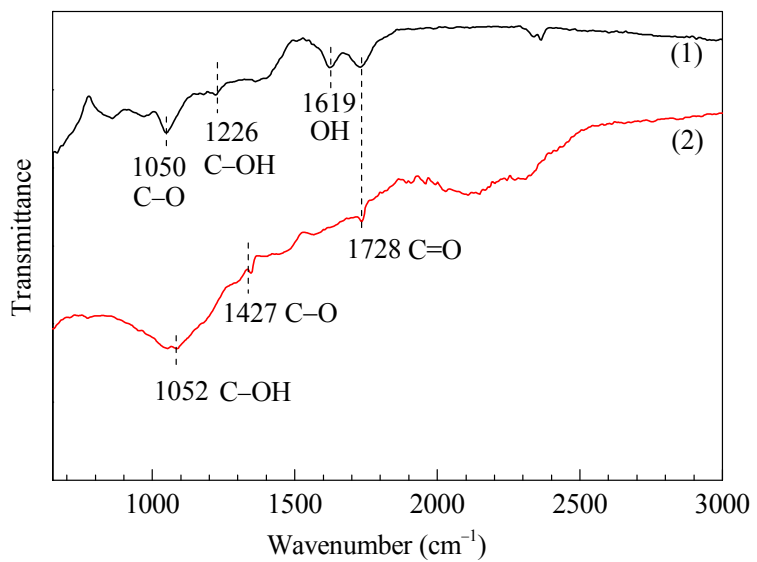

Fig. 5. FT-IR spectra of graphite oxide (1) and the RGO- $\mathrm{Ag}_{2} \mathrm{Se}$ composite (2).

sponding part of a type-II isotherm obtained with the given adsorption on the same surface area of the adsorbent in a non-porous form. Type-IV isotherms are exhibited by many mesoporous industrial adsorbents [25]. This indicates that the RGO- $\mathrm{Ag}_{2} \mathrm{Se}$ composite was mesoporous, with some wider pores where capillary condensation occurred. Fig. 6(b) illustrates the $\mathrm{BJH}$ pore-size distribution for the RGO- $\mathrm{Ag}_{2} \mathrm{Se}$ nanocomposite. It reveals that the pores in $\mathrm{RGO}-\mathrm{Ag}_{2} \mathrm{Se}$ possess a mean diameter of around $9 \mathrm{~nm}$. It can therefore be inferred that the pore structure of RGO- $\mathrm{Ag}_{2} \mathrm{Se}$ is highly desirable because the internal parts of catalysts will be readily accessible to reactant molecules during photocatalysis [26].

UV-Vis absorption spectra of the samples are presented in Fig. 7. The absorption edge for $\mathrm{RGO}-\mathrm{Ag}_{2} \mathrm{Se}$ is large compared with that for $\mathrm{Ag}_{2} \mathrm{Se}$. This means that the composite should have high photocatalytic activity under visible-light irradiation. The UV-Vis spectrum of RGO- $\mathrm{Ag}_{2} \mathrm{Se}$ showed a broad absorption peak centered at about $755 \mathrm{~nm}$, corresponding to a photon energy of $1.64 \mathrm{eV}$, which is similar to that reported for an $\mathrm{Ag}_{2} \mathrm{Se}$ complex photocatalyst [7]. $\mathrm{Ag}_{2} \mathrm{Se}$ is a I-VI semiconductor that belongs to the family of superionic conductors with potential applications like IR detectors, photovoltaic cells, magnetic resistive sensors, electrochemical potential memory, and semiconducting optical devices for the visible region [27-29]. When $\mathrm{Ag}_{2} \mathrm{Se}$ is coupled with graphene, graphene absorbs photoelec-

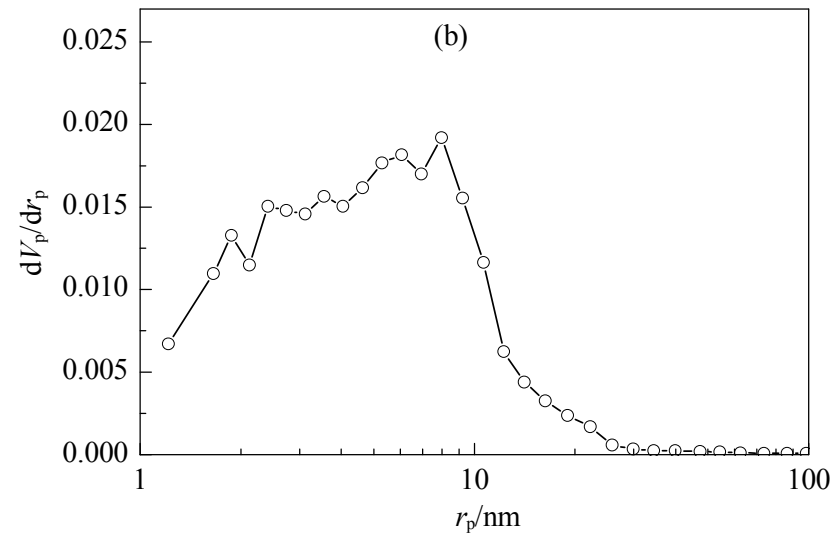

Fig. 6. $\mathrm{N}_{2}$ adsorption-desorption isotherm (a) and pore-size distribution (b) for the RGO- $\mathrm{Ag}_{2} \mathrm{Se}$ composite. 


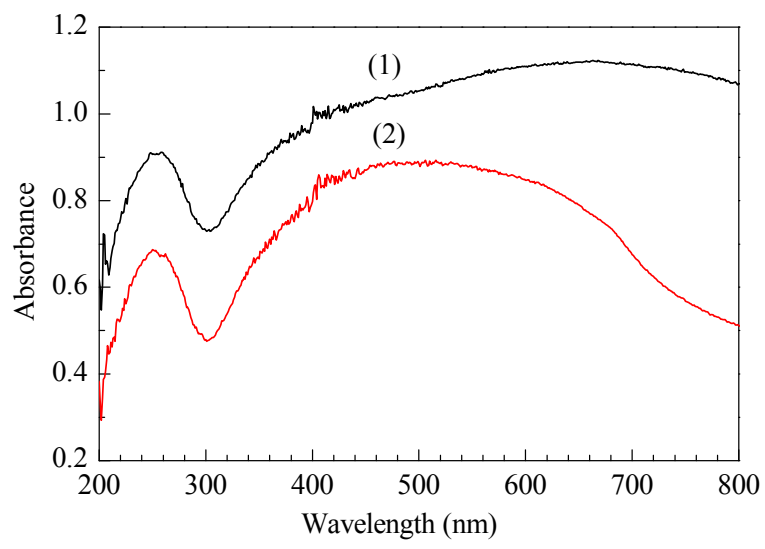

Fig. 7. UV-Vis absorption spectra of $\mathrm{Ag}_{2} \mathrm{Se}(1)$ and the RGO- $\mathrm{Ag}_{2} \mathrm{Se}$ composite (2).

trons, improving the excitation and injection of photoelectrons into the conduction band (CB) of $\mathrm{Ag}_{2} \mathrm{Se}$ [30]. This suggests that the absorption of $\mathrm{RGO}-\mathrm{Ag}_{2} \mathrm{Se}$ in the visible region is caused by the well-dispersed GONS rather than modification of the bandgap of $\mathrm{Ag}_{2} \mathrm{Se}$.

\subsection{Photocatalytic activity and generation of ROS}

The photocatalytic activity of the as-prepared nanocompo-
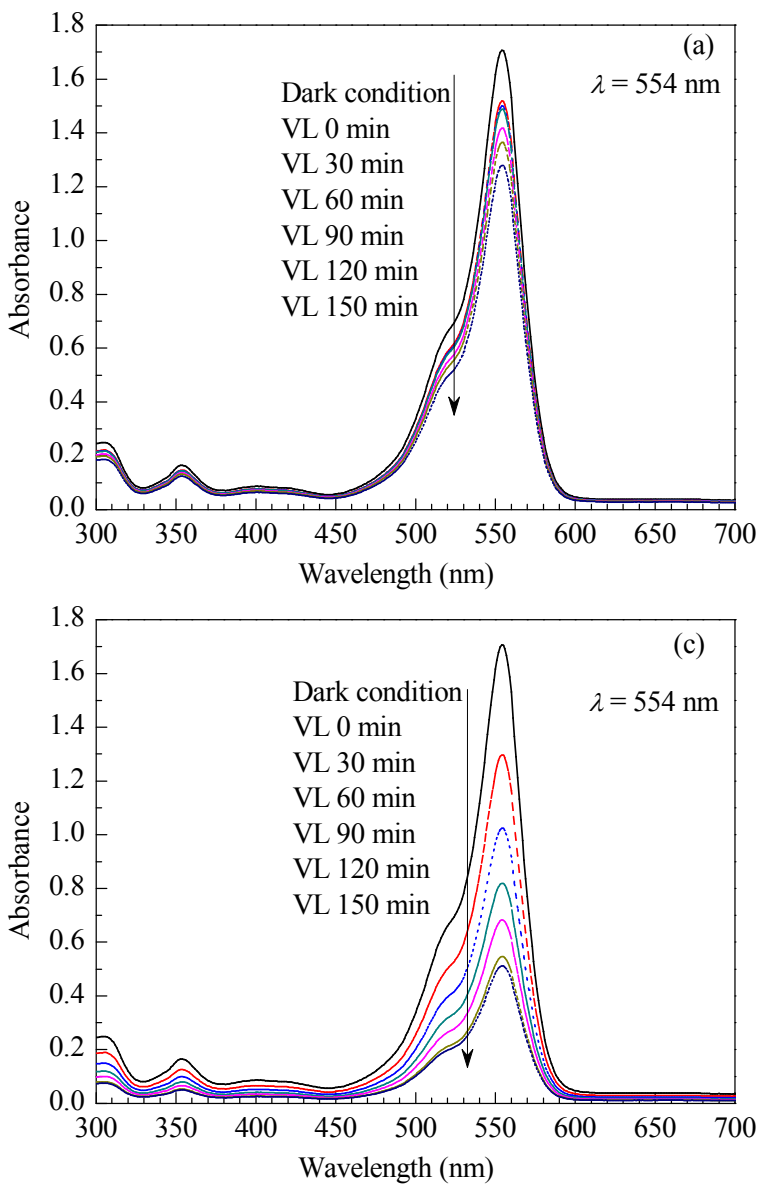

site was evaluated by catalytic degradation of RhB. The photocatalytic decomposition of dyes involves two steps: the adsorption of dye molecules and subsequent photodegradation. To evaluate the adsorption ability of the as-prepared composite catalyst, solutions of RGO- $\mathrm{Ag}_{2} \mathrm{Se}$ and control materials P25 and $\mathrm{Ag}_{2} \mathrm{Se}$ containing RhB were stirred magnetically for $120 \mathrm{~min}$ in the dark to establish adsorption-desorption equilibrium. In RGO- $\mathrm{Ag}_{2} \mathrm{Se}$, graphene acts as an adsorption support material because of its two-dimensional conjugated structure. Dye molecules adsorb on the surface of graphene via $\pi-\pi$ interactions [31]. To ascertain the adsorption ability of $\mathrm{P} 25, \mathrm{Ag}_{2} \mathrm{Se}$ and RGO-Ag $2 \mathrm{Se}$, the changes of RhB concentration were recorded and are shown in Fig. 8.

The photocatalytic performance of $\mathrm{P} 25, \mathrm{Ag}_{2} \mathrm{Se}$ and RGO- $\mathrm{Ag}_{2} \mathrm{Se}$ was determined by comparing the degradation efficiency of RhB under identical conditions of visible-light illumination ( $\lambda>420 \mathrm{~nm}$ ) (Fig. 8(d)); $C$ is the absorption of RhB at $554 \mathrm{~nm}$ and $C_{0}$ is the absorption of $\mathrm{RhB}$ after formation of an adsorption equilibrium on the photocatalyst before irradiation. A blank test (without any photocatalyst) exhibits little photolysis of RhB under visible light. Similarly, commercial P25 is obviously inactive under visible-light irradiation. In the case of RGO- $\mathrm{Ag}_{2} \mathrm{Se}$, the photodegradation efficiency reaches nearly $70 \%$ after 150 min of irradiation, which is nearly 3.5 times that of commercially available $\mathrm{TiO}_{2}$ (P25).

Fig. 9 depicts UV-Vis spectra of DPCO extracts in the pres-
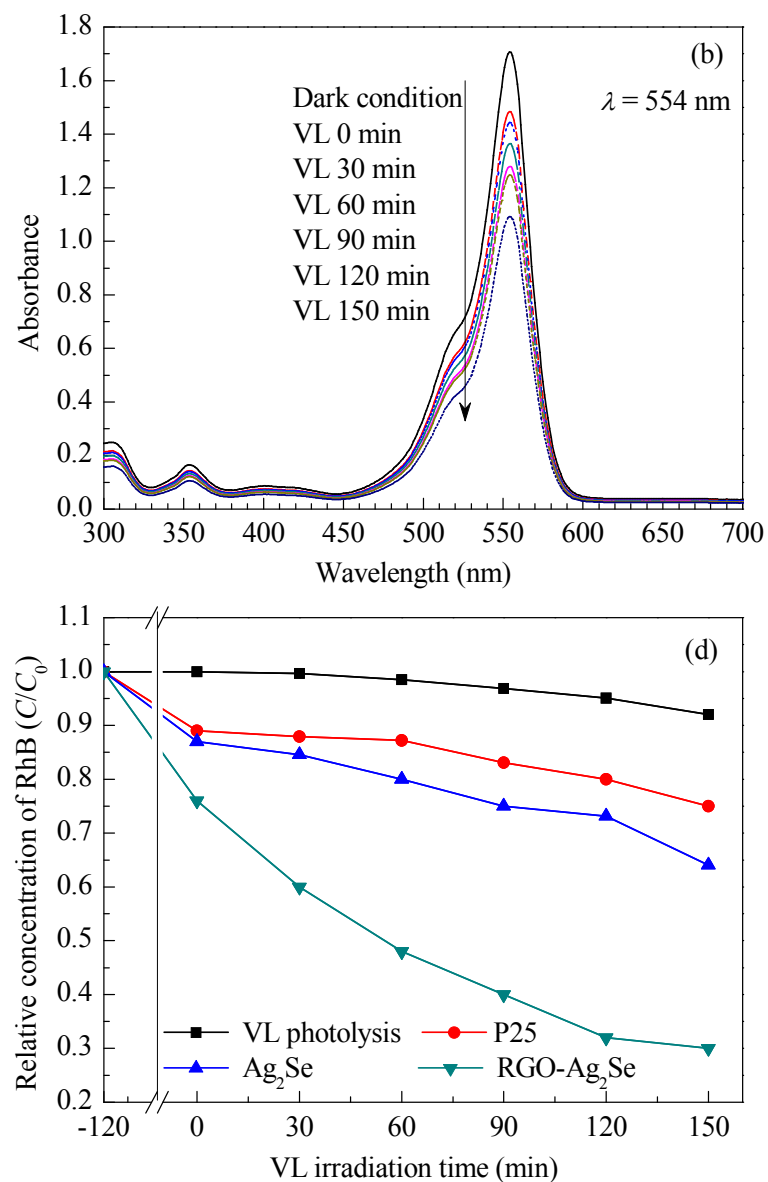

Fig. 8. UV-Vis absorption spectra for $\mathrm{RhB}$ degradation by $\mathrm{P} 25$ (a), $\mathrm{Ag}_{2} \mathrm{Se}$ (b), and $\mathrm{RGO}-\mathrm{Ag}_{2} \mathrm{Se}$ (c) under visible light (VL). (d) Plot of RhB degradation efficiency against VL irradiation time. 


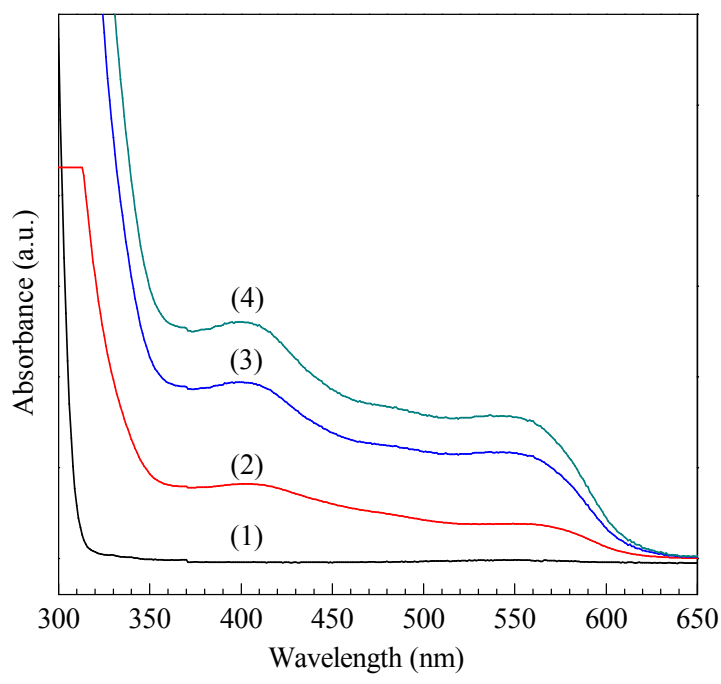

Fig. 9. UV-Vis spectra of extracts from a reaction of $\mathrm{RGO}-\mathrm{Ag}_{2} \mathrm{Se}$ with DPCI to DPCO by oxidation under VL irradiation for different periods (1) $0 \mathrm{~min}$; (2) $60 \mathrm{~min}$; (3) $90 \mathrm{~min}$; (4) $120 \mathrm{~min}$.

ence of RGO- $\mathrm{Ag}_{2} \mathrm{Se}$ under ultrasonic irradiation. DPCI can be oxidized to form DPCO. Under ultrasonic irradiation, some electrons transition from the valence band (VB) to the $\mathrm{CB}$ of DPCI. Simultaneously, electron-hole pairs form on the surface or inside RGO- $\mathrm{Ag}_{2} \mathrm{Se}$. The electrons and holes react with the $\mathrm{O}_{2}$ dissolved in aqueous solution and $\mathrm{H}_{2} \mathrm{O}$ adsorbed on the surface of $\mathrm{RGO}-\mathrm{Ag}_{2} \mathrm{Se}$, respectively, producing superoxygen radical anions $\left(\bullet \mathrm{O}_{2}{ }^{-}\right)$and hydroxyl radicals $(\bullet \mathrm{OH})$, respectively. $\bullet \mathrm{OH}$ oxidizes DPCI into DPCO. DPCO can be extracted into benzene and absorbs at $560 \mathrm{~nm}$, allowing the production of $\bullet \mathrm{OH}$ to be easily detected. The absorption of extracts from this reaction solution depended on irradiation time, showing an obvious increase in DPCO concentration compared with that of the corresponding solution that was not irradiated [32]. The above results suggest that $\mathrm{RGO}-\mathrm{Ag}_{2} \mathrm{Se}$ is efficient at generating ROS.

To demonstrate the photocatalytic activity and cycling performance of the RGO- $\mathrm{Ag}_{2} \mathrm{Se}$ photocatalyst, consecutive photocatalytic reactions to degrade TBA were conducted in the presence of RGO- $\mathrm{Ag}_{2} \mathrm{Se}$ under visible light. The color of the dye

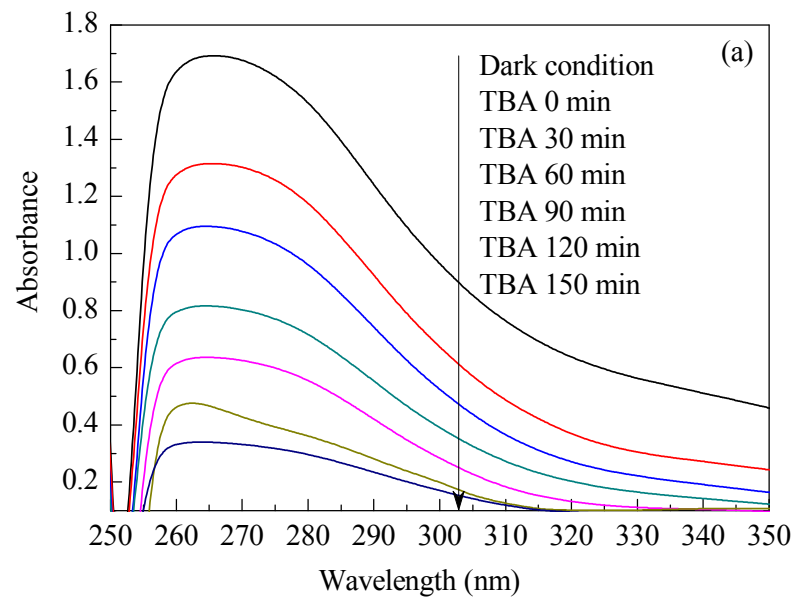

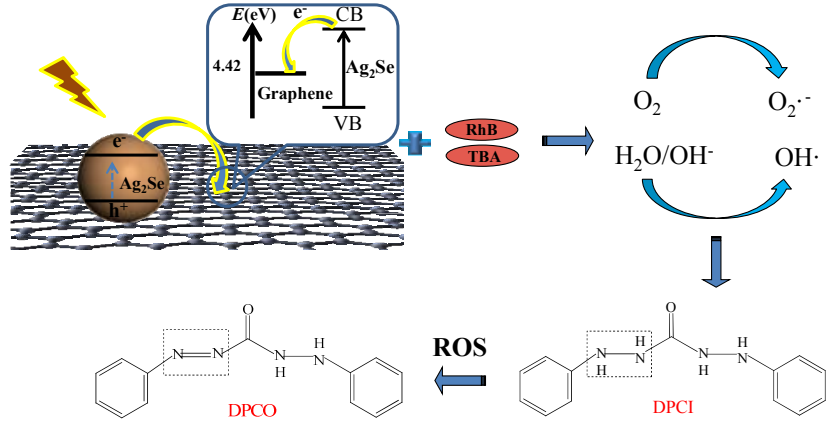

Fig. 11. Schematic diagram of the degradation of $\mathrm{RhB}$ and TBA dyes and ROS generation on the interface of $\mathrm{RGO}-\mathrm{Ag}_{2} \mathrm{Se}$ under VL irradiation.

solution increasingly weakened as the dye concentration decreased. The decrease in concentration of TBA was evaluated at $375 \mathrm{~nm}$, which is the $\lambda_{\max }$ of TBA (determined from its absorption spectrum). After 150 min, RGO-Ag 2 Se degraded $74.2 \%$ of TBA, as shown in Fig. 10(a). Fig. 10(b) reveals that RGO- $\mathrm{Ag}_{2} \mathrm{Se}$ maintained its photocatalytic activity after four runs of TBA degradation. These results indicate that the RGO- $\mathrm{Ag}_{2} \mathrm{Se}$ photocatalyst has high stability and is not photocorroded during photocatalytic oxidation of TBA. Thus, $\mathrm{RGO}-\mathrm{Ag}_{2} \mathrm{Se}$ is promising for practical photocatalyst applications in environmental purification. Graphene modification improves not only the photocatalytic performance but also the long-term stability of $\mathrm{Ag}_{2} \mathrm{Se}$ nanocrystals. These results are important from a practical viewpoint, because the enhanced photocatalytic activity and stability of RGO- $\mathrm{Ag}_{2} \mathrm{Se}$ will lead to more cost-effective operation.

A schematic diagram of the charge transfer process between $\mathrm{Ag}_{2} \mathrm{Se}$ and graphene is illustrated in Fig. 11. When RGO-Ag $\mathrm{Se}$ was illuminated with visible light, $\mathrm{Ag}_{2} \mathrm{Se}$ produced electrons and holes with sufficient energy or momentum to overcome the energy barrier (denoted as $E_{\mathrm{g}}$ ). The electrons traveled from the VB to the $\mathrm{CB}$, increasing the number of electrons in the $\mathrm{CB}$ and holes in the VB. Thus, a number of electrons and holes were generated in $\mathrm{Ag}_{2} \mathrm{Se}$. Graphene attached to $\mathrm{Ag}_{2} \mathrm{Se}$ aided the transfer of electrons to the $\mathrm{CB}$ of $\mathrm{Ag}_{2} \mathrm{Se}$, thereby increasing the number of excited electrons as well as the rate of elec-

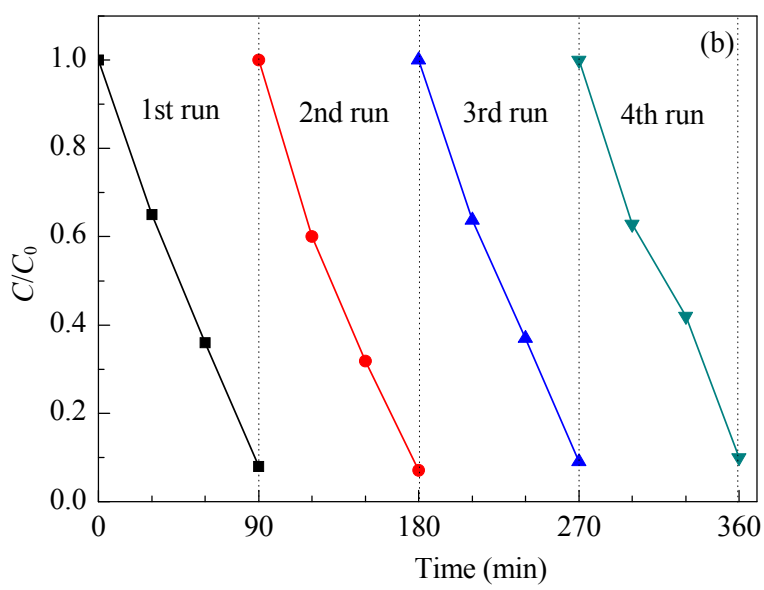

Fig. 10. UV-Vis spectra (a) and cycling runs (b) showing the photodegradation of TBA by RGO- $\mathrm{Ag}_{2} \mathrm{Se}$ under VL irradiation. 
tron-induced redox reactions. Based on the above discussion, the presence of graphene in the RGO- $\mathrm{Ag}_{2} \mathrm{Se}$ nanocomposite not only improved its visible-light absorption intensity but also enhanced photocatalytic activity because charge separation was facilitated by the synergistic interaction between graphene and $\mathrm{Ag}_{2} \mathrm{Se}$. The generated electrons $\left(\mathrm{e}^{-}\right)$reacted with dissolved oxygen molecules to produce $\mathrm{O}_{2} \bullet^{-}$. Positively charged holes $\left(\mathrm{h}^{+}\right)$ can react with $\mathrm{OH}^{-}$derived from $\mathrm{H}_{2} \mathrm{O}$ to form $\mathrm{OH} \bullet$ [33]. $\mathrm{RhB}$ and TBA molecules can then be photocatalytically degraded by $\mathrm{O}_{2} \bullet-$ and $\mathrm{OH} \bullet$ to form $\mathrm{CO}_{2}, \mathrm{H}_{2} \mathrm{O}$ and other mineralization products. The reactions involved in the charge transfer and mineralization of these dyes are as follows:

$$
\begin{gathered}
\text { RGO-Ag } \mathrm{Se}+\mathrm{VL}(h v) \rightarrow \mathrm{RGO}-\mathrm{Ag}_{2} \mathrm{Se}^{+}+\mathrm{h}^{+}+\mathrm{e}^{-} \\
\mathrm{H}_{2} \mathrm{O} \rightarrow \mathrm{H}^{+}+\mathrm{OH}^{-} \\
\mathrm{h}^{+}+\mathrm{OH}^{-} \rightarrow \mathrm{OH} \bullet \\
\mathrm{O}_{2}+\mathrm{e}^{-} \rightarrow \mathrm{O}_{2} \bullet
\end{gathered}
$$

$\mathrm{RhB} / \mathrm{TBA}+\mathrm{OH} \bullet+\mathrm{O}_{2} \bullet^{-} \rightarrow \mathrm{CO}_{2}+\mathrm{H}_{2} \mathrm{O}+$ mineralized by-products

\section{Conclusions}

A visible-light photocatalyst $\mathrm{RGO}-\mathrm{Ag}_{2} \mathrm{Se}$ was prepared by a sonochemical-assisted hydrothermal method. XRD analysis of the RGO- $\mathrm{Ag}_{2} \mathrm{Se}$ composite suggested that the $\mathrm{Ag}_{2} \mathrm{Se}$ particles were predominantly orthorhombic crystalline phase. SEM images showed that $\mathrm{Ag}_{2} \mathrm{Se}$ nanoparticles were attached to the graphene sheets. EDX confirmed that the composite was mainly composed of $\mathrm{Ag}$, Se, and $\mathrm{C}$. The photocatalytic activity of $\mathrm{RGO}-\mathrm{Ag}_{2} \mathrm{Se}$ was examined by degradation of organic and industrial dyes in aqueous solution under visible-light irradiation. These results reveal that graphene is an excellent supporting material for semiconductor nanoparticles because it acts as an electron acceptor and transporter. UV-Vis data re- vealed the large absorption edge of RGO- $\mathrm{Ag}_{2} \mathrm{Se}$, which makes it useful as a photocatalyst that is active under visible light.

\section{References}

[1] Ghosh T, Cho K Y, Ullah K, Nikam V, Park C Y, Meng Z D, Oh W C. J Ind Eng Chem, 2013, 19: 797

[2] Helmes C T, Sigman C C, Fung V A, Thompson K, Doeltz M K, Mackie M, Klein T E, Lent D. J Environ Sci Health A, 1984, 19: 97

[3] Pazarbasi M B, Kocyigit A, Ozdemir G, Yasa I, Karaboz I. Fresen Environ Bull, 2012, 21: 1410

[4] Rauf M A, Meetani M A, Khaleel A, Ahmed A. Chem Eng J, 2010, 157: 373

[5] Aliabadi M, Ghahremani H, Izadkhah F, Sagharigar T. Fresen Environ Bull, 2012, 21: 2120

[6] Das V D, Karunakaran D. Phys Rev B, 1989, 39: 10872

[7] Cao H Q, Xiao Y J, Lu Y X, Yin J F, Li B J, Wu S S, Wu X M. Nano Res, 2010, 3: 863

[8] Haubner K, Murawski J, Olk P, Eng L M, Ziegler C, Adolphi B, Jaehne E. Chem Phys Chem, 2010, 11: 2131

[9] Lupo F, Kamalakaran R, Scheu C, Grobert N, Rühle M. Carbon, 2004, 42: 1995

[10] Zhang X Y, Li H P, Cui X L, Lin Y H. J Mater Chem, 2010, 20: 2801

[11] Abdullah A Z, Ling P Y. J Hazard Mater, 2010, 173: 159

[12] Khallaf H, Chen C T, Chang L B, Lupan O, Dutta A, Heinrich H, Shenouda A, Chow L. Appl Surf Sci, 2011, 257: 9237

[13] Wu N, Losovyj Y B, Wisbey D, Belashchenko K, Manno M, Wang L, Leighton C, Dowben P A.J Phys Condens Matter, 2007, 19: 156

[14] Nilsun H I, Gökce T G. Ultrasonics, 2004, 42: 591

[15] Tai G A, Guo W L. Ultrason Sonochem, 2008, 15: 350

[16] Meng Z D, Zhu L, Oh W C. J Ind Eng Chem, 2012, 18: 2004

[17] Zhu L, Ghosh T, Park C Y, Meng Z D, Oh W C. Chin J Catal (催化学 报), 2012, 33: 1276

[18] Oh W C, Zhang F J. Asia J Chem, 2011, 23: 875

[19] Chen X J, Xu H H, Wang Y J, Hu S, Zhang Z X, Zhang Y M. Agric Sci

\section{Graphical Abstract}

Chin. J. Catal., 2015, 36: 603-611 doi: 10.1016/S1872-2067(14)60275-8

Modified hydrothermal synthesis and characterization of reduced graphene oxide-silver selenide nanocomposites with enhanced reactive oxygen species generation

Lei Zhu, Shu Ye, Asghar Ali, Kefayat Ulla, Kwang Youn Cho, Won-Chun Oh*

Hanseo University, Korea; Korea Institute of Ceramic Engineering and Technology, Korea

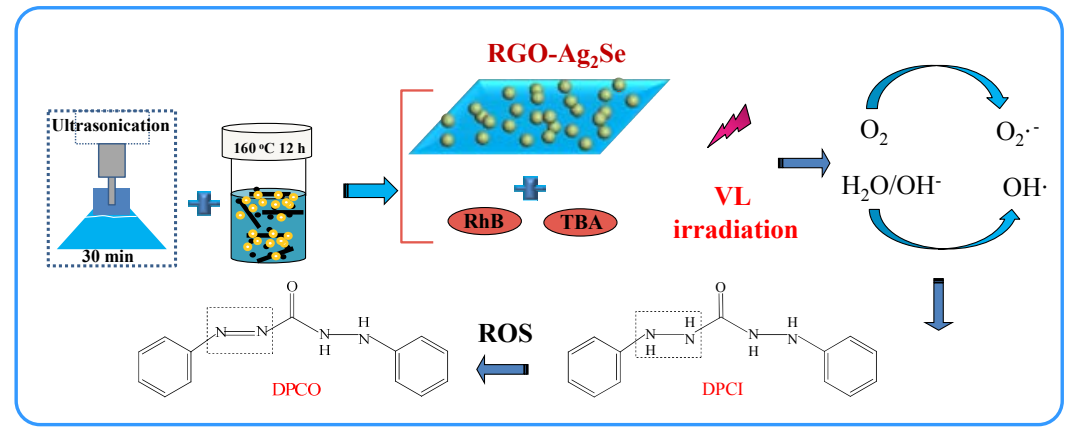

A visible-light photocatalyst composed of reduced graphene oxide and $\mathrm{Ag}_{2} \mathrm{Se}$ nanoparticles is prepared via a facile sonochemical-assisted hydrothermal method. The ability of this photocatalyst to degrade organic dye rhodamine B and industrial dye Texbrite BA-L and generate reactive oxygen species under visible-light irradiation is evaluated. 
China, 2007, 6: 458

[20] Yang X Y, Zhang X Y, Ma Y F, Huang Y, Wang Y S, Chen Y S. J Mater Chem, 2009, 19: 2710

[21] Chen G Y, Wang D J, Liang C, Wei Z Y, Zhang W X, Liang J C, Wang D M. Rare Metal Mater Eng, 2012, 41: 1153

[22] Yu C C, Yu M, Li C X, Zhang C M, Yang P P, Lin J. Cryst Growth Des, 2009, 9: 783

[23] Oh W C, Chen M L, Zhang K, Zhang F J, Jang W K, Zhang F J. J Korean Phys Soc, 2010, 56: 1097

[24] Zhan Y Q, Meng F B, Lei Y J, Zhao R, Zhong J C, Liu X B. Mater Lett, 2011, 65: 1737

[25] Shigesato Y, Murayama A, Kamimori T, Matsuhiro K. Appl Surf Sci,
1988, 33: 804

[26] Krings L H M, Talen W. Sol Energy Mater Sol Cells, 1998, 54: 27

[27] Chen R Z, Xu D S, Guo G L, Tang Y Q.J Mater Chem, 2002, 12: 1437

[28] Wuttig M. Nat Mater, 2005, 4: 265

[29] Schoen D T, Xie C, Cui Y.J Am Chem Soc, 2007, 129: 4116

[30] Meng Z D, Ullah K, Zhu L, Ye S, Oh W C. Mater Sci Semicon Proc, 2014, 27: 173

[31] Low J X, Yu J G, Li Q, Cheng B. Phys Chem Chem Phys, 2014, 16: 1111

[32] Meng Z D, Ghosh T, Zhu L, Choi J G, Park C Y, Oh W C.J Mater Chem, 2012, 22: 16127

[33] Munter R. Proc Estonian Acad Sci Chem, 2001, 50: 59 